\title{
First use of participatory Bayesian modeling to study habitat management at multiple scales for biological pest control
}

\author{
Nicolas Salliou $^{1,2}$ (D) Aude Vialatte ${ }^{1,3} \cdot$ Claude Monteil $^{1,3} \cdot$ Cécile Barnaud $^{1}$
}

Accepted: 5 December 2018 / Published online: 7 January 2019

(C) INRA and Springer-Verlag France SAS, part of Springer Nature 2019

\begin{abstract}
Habitat management is increasingly considered as a promising approach to favor the ecosystem service of biological control by enhancing natural enemies. However, habitat management, whether at local or landscape scale, remains very uncertain for farmers. Interactions between ecological processes and agricultural practices are indeed uncertain and site-specific, which makes implementation difficult. Thus, prospecting innovations based on habitat management may benefit from integrating local stakeholders and their knowledge. Our objective is to explore with both local and scientific stakeholders how they perceive agricultural practices, ecological processes, and services related to biological pest control and habitat management. We conducted a participatory Bayesian Network modeling approach with five stakeholders in Southwest France around apple orchard cultivation. We co-constructed such Bayesian Networks based on participants' knowledge. We explored scenarios favoring natural enemies and habitat manipulation with each participant's Bayesian Network. We compared how different stakeholders perceive the impact of each scenario on the biological control ecosystem service. Our results indicate that a landscape with a high proportion of seminatural habitats does not translate into significant biological control for most participants even though some stakeholders perceive a significant impact on generalist predators' activity within orchards. For these local stakeholders, habitat management at the orchard level such as inter-row vegetation seems currently more promising than at the landscape scale. Here, we show for the first time that the use of Bayesian modeling in a participatory manner can give precious insights into the most promising perspectives on habitat management at different scales. These different local perspectives suggest in particular that further dialogue between ecologists and local stakeholders should be sought about inter-row habitat management as the most promising practice to foster biological pest control and other ecosystem services.
\end{abstract}

Keywords Apple orchards $\cdot$ Biological pest control $\cdot$ Semi-natural habitats $\cdot$ Participatory Bayesian network $\cdot$ Stakeholder perspective

\section{Introduction}

There is a growing worldwide concern regarding agriculture's impact on ecosystems. Pesticides are known for their negative effects on biodiversity and human health. Nowadays, many

Nicolas Salliou

nsalliou@ethz.ch

1 UMR 1201 Dynafor, INRA, 24 chemin de Borde Rouge, 31326 Castanet Tolosan Cedex, France

2 D-BAUG, IRL, Planning of Landscape and Urban Systems (PLUS), ETH Zürich, Stefano-Franscini-Platz 5, CH-8093 Zürich, Switzerland

3 INP-ENSAT, University of Toulouse, BP 32607, 31326 Castanet Tolosan, France public policies aim at reducing pesticide use and subsidize less pesticide intensive practices. In France, for example, the Écophyto public policy aims at reducing pesticide use by $50 \%$ by 2025 . In this context, agroecology appears as a promising approach (Duru et al. 2015). This approach seeks to make use of biodiversity to increase agricultural production or limits chemical inputs. For example, it may use natural enemies of insect pests for biological control instead of using pesticides. Nowadays, integrated pest management (IPM) is a widely used strategy based on pests and natural enemies monitoring to optimize pesticide applications and substitute them with biological control when economically sound. Habitat management appears as a promising complementary strategy to IPM to enhance biological control by providing resources, alternative preys or hosts, and shelter from adverse conditions (Schellhorn et al. 2015). In orchards, it may imply changes at 
both the plot and landscape levels: management of ground covers, understory plants, and plant assemblages at plot scale (Simon et al. 2010) and management of semi-natural habitats at landscape scale (Veres et al. 2013).

Even though underlying ecological processes linked with these habitats at orchards plot and landscape scale have been extensively studied (Maalouly et al. 2013 and review in Simon et al. 2010), mobilizing habitat management within agroecosystems to provide pest control ecosystem services to farmers remains poorly studied, and benefits are often implicitly assumed rather than explicitly demonstrated (Griffiths et al. 2008). Uncertainties related to the variability of ecological responses make the design of landscapes favoring biological pest control to farmers difficult. In the specific case of orchards, few studies addressed the correlation between the specific features of the agricultural area and benefits of pest control to farmers, like lower pesticide use or less fruit damage (Simon et al. 2010). Most field experiments in orchards remained at the plot scale with herbaceous plants (Simon et al. 2010). The available knowledge about ecological processes at local and landscape scale and their relation to ecosystem services to farmers by habitat management is so far insufficient for implementation (Simon et al. 2010).

Even though uncertainties are high, landscape-scale management of pest control ecosystem services remains a promising approach as farmers indicate their willingness to cooperate to do so (Stallman and James 2015), and computer modeling indicates significant potential benefits for farmers (Bell et al. 2016). Yet, no study has actually considered stakeholders' perspectives in order to see how landscape ecology findings about habitat management could be used to foster pest control ecosystem services. Very few field experiments exist (Simon et al. 2010), and case studies of farmers implementing landscape-scale habitat management to foster biological control are scarce (Sigwalt et al. 2012). According to Duru et al. (2015), the lack of practical application and design of biodiversity-based agriculture is due to high uncertainties about relations between agricultural practices, ecological processes, and ecosystem services as well as the sitespecific character of agroecological practices. They suggest that participatory modeling approaches mixing experiential and scientific knowledge have the potential to foster innovations towards biodiversity-based agriculture because they enable to (1) explicitly acknowledge uncertainties, (2) integrate local specificities, and (3) cover social as well as ecological dimensions surrounding farming activities. Modeling is especially necessary when direct experimentation is difficult due to the scale of innovations (e.g., manipulating habitats at a landscape scale) and time span (e.g., a hedgerow needs several years to grow). Moreover, participatory modeling allows to integrate both scientific knowledge and local stakeholders' knowledge, which is critical for innovations in the field of habitat management for biological pest control (Steingröver et al. 2010). In this paper, we propose to explore through a participatory modeling and scenario prospection approach how different stakeholders perceive agricultural practices, ecological processes, and ecosystem services at stake in biological pest control and habitat management within orchards. Doing so, we also describe key steps in the process to integrate stakeholder's knowledge into such participatory process (Fig. 1).

\section{Material and method}

\subsection{Case study background and participants}

Our study was conducted in the southwest of France in an agricultural region where alluvial terraces along the Aveyron and Tarn rivers are specialized in fruit tree production. The majority of orchards in the area are under apple production. Other orchards are under plum, peaches, pear, kiwi, and cherry production. The other major crop in the studied area is maize, which regularly separates fruit farms from one another in the landscape. Both orchards and maize production are irrigated using waters from the Aveyron or Tarn rivers. The majority of apple producers in the area are conventional producers involved in long supply chains towards grocery stores and supermarkets. Even though it is a strategy on the rise, a minority of producers are certified organic and/or sell directly to consumers.

Four local stakeholders involved in the fruit tree production sector participated in our research process. These four participants are as follows: a conventional apple producer, an organic apple producer, the farm manager of the local agricultural high school, and a fruit tree advisor from a local experimentation center. A fifth participant is a landscape ecologist conducting research on biological control by conservation. Hence, we combined empirical knowledge (farmers), technical knowledge (advisor and high school farm manager), and scientific knowledge (researcher), which are three major types

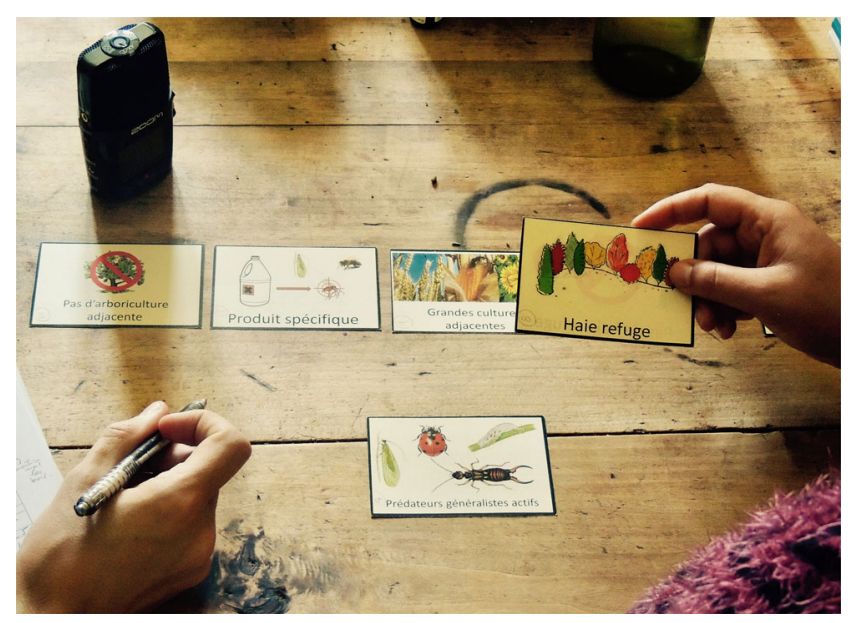

Fig. 1 Individual parametrization of the Bayesian Network. Cards with imagery for each node and state of the network facilitates the conditional probability elicitation by participants 
of knowledge that are important to take into account in agricultural innovation (Girard and Navarrete 2005). Besides, both producers represent the two ends of a spectrum regarding orchardists' protection strategy at the farm level. The organic producer has high environmental concerns, uses no synthetic pesticides, and compensates lower yields with high selling prices. The conventional producer aims at high yields and visual quality by using mainly synthetic pesticides and is constrained by low prices. As for the advisor and the high school farm manager, they deal with both organic and conventional orchards.

\subsection{Modeling approach}

Our participatory modeling approach followed three main steps:

1. During two collective workshops, participants established a conceptual model of the socio-ecological system (SES) at stake around the issue of biological control. To do so, we used the ARDI (Actor-Resource-Dynamic-Interaction) method, which is designed to build a conceptual model of an SES together with stakeholders (Etienne et al. 2011). Participating stakeholders are accompanied by a facilitator in a series of workshops in order to build collectively a conceptual model of an SES representing its key actors (humans and non-humans), its key resources, their dynamics (processes which drive changes), and the interactions connecting them. The first workshop focused on listing Actors (A), Resources (R), and Dynamics (D). The second workshop was about synthesizing and connecting previously identified actors, resources, and dynamics to form the final Interaction (I) diagram. This interaction diagram is the final conceptual model of the SES.

2. During another workshop, the ARDI conceptual model was collectively turned into a Bayesian Network (BN) by participants. Each component of the conceptual model was translated into a node of a hierarchical causality network. Such a hierarchical causality network forms the structure of a BN. Nodes which are influencing other nodes by causality links are called "parent nodes," while influenced nodes are called "child nodes." Nodes' states were also defined by participants. Nodes' states describe all situations that can be encountered about that node. For example, participants considered that the neighboring fields of grain growers could be under three potential land covers (or states): crop, meadow, or forest. The structure of the obtained network with agreed states prior to individual parametrization is shown in Fig. 2 (for more details on nodes and states collectively discussed and agreed by participants, please refer to Table 2 in Salliou and Barnaud (2017)).
3. During a final individual interview, we facilitated the parametrization of the BN for each participating stakeholder according to his own representation of how the SES works. This process implies for each node of the network to elicit the probability that each of its states will occur for all combinations of states of the parent nodes. All these probabilities constitute a Conditional Probability Table (CPT). The probabilities for each state of root nodes (i.e., nodes without parent nodes) were also elicited. Each participant thus elicited in their individual interview 258 conditional probabilities constituting their CPT and 8 probabilities about root nodes. The final BN of each participant, compiling the common BN structure and states with individual CPT, was compiled by the Netica software (V5.18), a specialized software in Bayesian modeling. This program was used for inferring scenarios.

\subsection{Scenario exploration}

Bayesian Networks can be used in a top-down manner for scenario and impact analysis. Top-down means that it is possible to change the probability laws of one or several parent nodes and analyze how states of nodes situated in lower parts of the network's hierarchy have their state's distribution changed (Düspohl et al. 2012). With each of the individual $\mathrm{BN}$, we simulated five scenarios related to biological control and habitat management. We distinguished three types of scenarios: (a) scenarios 1 and 2 explore the impact of ecological processes on ecosystem services, (b) scenarios 3 and 4 are about habitat management at landscape and orchard-scale respectively, (c) scenario 5 explores a more radical redesign scenario with habitat management at both scales associated with other biological control friendly practices:

- Scenario 1: Aphelinus mali's presence in the orchard is certain. Aphelinus mali is a parasitoid wasp laying its eggs in Woolly aphids' (Eriosoma lanigeruim) bodies. Woolly aphids spoils apples by favoring fungus development (Weber and Brown 1988). We parametrized the Bayesian Networks with the "presence" state of the "Aphelinus mali" node at $100 \%$ (absolute certainty of presence).

- Scenario 2: Generalist predators' activity is certain. Ladybugs, lacewings, earwigs, and many others are quite commonly found in apple orchards where they can predate on aphids and spider mites (Symondson et al. 2002). We parametrized the Bayesian Networks with the "Active" state of "Generalist predator" node $=100 \%$.

- Scenario 3: Landscape with a high proportion of seminatural habitats. Findings in landscape ecology suggest that a high proportion of semi-natural habitats in an agricultural landscape favors biological pest control 


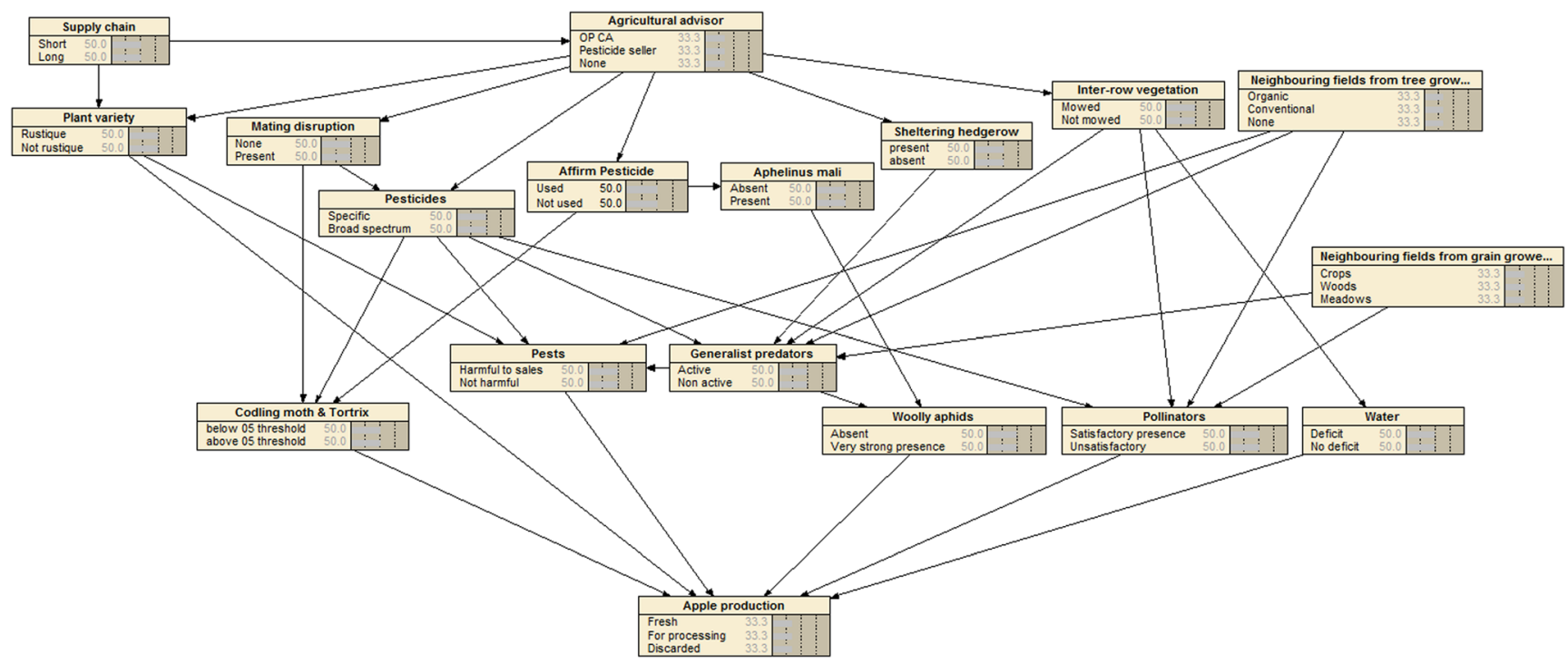

Fig. 2 Hierarchical structure and nodes' states of the Bayesian Network constructed by participants prior to parametrization of probabilities

(Rusch et al. 2016). We parametrized the Bayesian Networks with "presence" state of "sheltering hedgerow" node at 100\%, "woods" and "meadows" states of "neighboring fields of grain growers" node at $50 \%$ each, and the "no orchards" state of "neighboring fields from fruit growers" node at $100 \%$.

- Scenario 4: Inter-row vegetation of apple orchards left unmowed. Findings suggest that a decreasing mowing frequency in the alleys of orchards increased the densities of natural enemies (Horton et al. 2003). We parametrized the Bayesian Networks with the "not mowed" state of "inter-row vegetation" node at $100 \%$.

- Scenario 5: Systemic change of all agricultural practices favorable to natural enemies. The transition towards sustainable farm management may require a system redesign (Hill and MacRae 1995) and the consistent change of all farming practices towards biological pest control rather than a step-by-step change (Meynard et al. 2012). We parametrized the Bayesian Networks with scenario 3 and 4 parametrization and we also added the "specific" state of "pesticide" node at $100 \%$, the "presence" state of "mating disruption" node at $100 \%$, and the "rustic" state of "plant variety" node at $100 \%$.

We analyzed the impact of each scenario on the BN of each participant by comparing probability laws for impacted child nodes before and after applying the new parametrization of this scenario. For example, if a scenario increases the probability to have active generalist predators from 30 to $40 \%$, we consider that there is a " $\Delta$ probability" for this state of +10 . For each scenario, we first focused on the impact on the "apple production" node probability distribution of each participant's BN. The impact on the "apple production" node gives a direct indication on the evolution of benefit as perceived by each participant. We focus our analysis on the probability variation of the "Fresh" state (apples with no appearance defect), which is the quality state with the highest selling price. As the variation of benefit is derived from changes in ecological variables, we considered this benefit as an ecosystem service. We also compared the impacts obtained by each participant's $\mathrm{BN}$, thus allowing the identification of consensus and ambiguity among participants about the effect of scenarios (Salliou et al. 2017), ambiguity being the simultaneous presence of different ways of framing a situation.

\section{Results and discussion}

In this section, we introduce the results obtained from the exploration of the five scenarios introduced in the above section (Section 2.3). The impacts of each scenario on the "apple production" node as a variation of the "fresh" state probability are presented in Fig. 3.

\subsection{Scenario 1: Aphelinus mali's presence in apple orchards is certain}

All participants' BN except the conventional producer's indicated an increase in the probability of fresh apple production. The conventional producer's BN indicated no effect. For all other participants, their BNs indicated benefits from an enhanced presence of Aphelinus mali with probability increases ranging from +5.4 to +8.1 . As an indication of the magnitude, a 5-point increase in fresh sales means an approximate gross profit of $1000 €$ per hectare for a conventional orchard in the area (with variations depending on many variables like the variety, market prices, and yearly yield. Organic prices can be twice as high as conventional ones, but yields are usually 
Fig. 3 Impact of scenarios on the "apple production" node for the probability of its state to be "fresh" according to five participants (A: advisor; O: organic farmer; $\mathrm{C}$ : conventional farmer; P: pedagogic farm manager; E: ecologist)

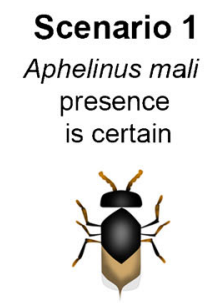

$\Delta$

Probability

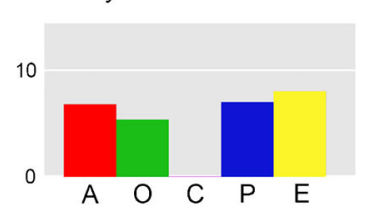

A O C P E

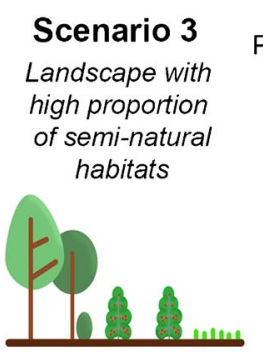

$\Delta$

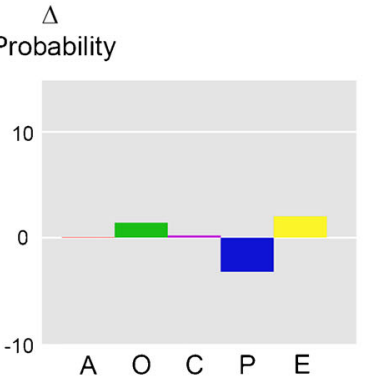

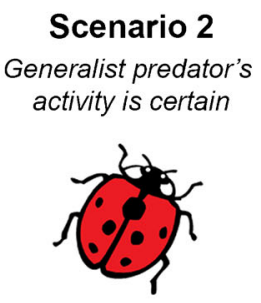
Probability
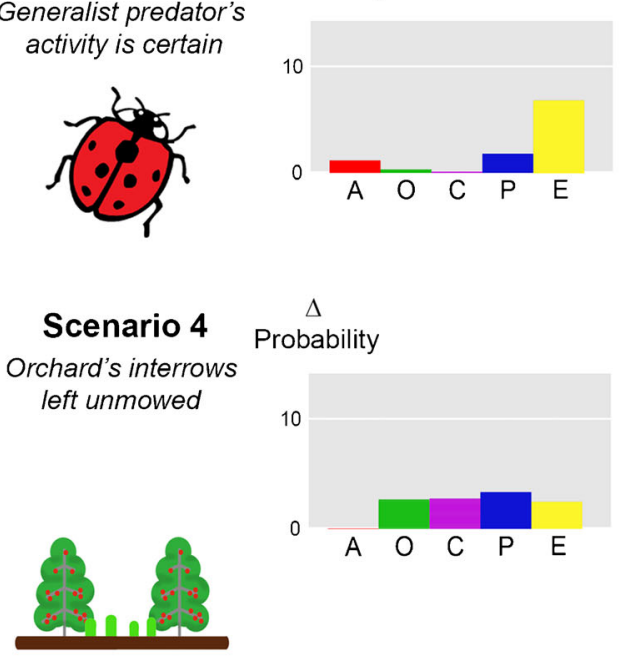

$\Delta$

Probability

10

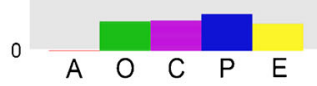

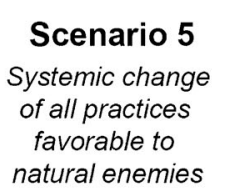

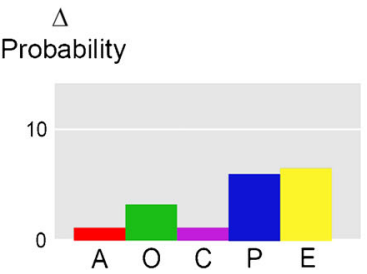

significantly lower). In the BN structure (Fig. 2), only the "Affirm" node may influence the "Aphelinus mali" node. A complementary analysis explored the scenario effect of not using the Affirm pesticide on Aphelinus mali. The impact is null for four participants; for the pedagogic farm manager, however, the absence of this pesticide is detrimental to Aphelinus mali's presence (-12). This last result is surprising as it suggests that Aphelinus mali might be favored by a pesticide. This surprising result is the logical consequence of the impossibility to assign some probabilities in the CPT by this stakeholder during the elicitation phase. For such a situation, a normal distribution is used to populate the unpredictable probabilities (Salliou et al. 2017). As a consequence, this result should be taken with caution.

Aphelinus mali seems to be an efficient natural enemy related to ecosystem services significant to apple producers. However, according to the participants, there is no agricultural practice which could enhance its parasitism rate and thus favor higher production benefits for farmers. The Aphelinus mali scenario showed that according to participants, this natural enemy had the highest potential to provide a significant biological control ecosystem service. This potential has been known for many years, as Aphelinus mali acclimation was undertaken worldwide in the late 1920s. If we consider the $\mathrm{BN}$ structure as defined by the participants, there is little action that stakeholders may enforce to favor Aphelinus mali. First, in the $\mathrm{BN}$ structure itself, there is no relation between the landscape variables (i.e., the "sheltering hedgerow" node and nodes about neighboring fields) and the "Aphelinus mali" node. Previous interviews in the area have also shown that local farmers and their advisors do not perceive any effect of the landscape on Aphelinus mali (Salliou and Barnaud 2017) even though it has been shown in Chilean apple orchards that hedgerows with Pyracantha (Pyracantha coccinea) provide a positive effect on Aphelinus mali (Ortiz-Martínez et al. 2013). Second, the "Affirm pesticide" node connected with the Aphelinus mali node (Fig. 2) revealed no negative impact on Aphelinus mali, probably because this pesticide is used in summer when Aphelinus mali populations are regularly very significant (Mols 1996).

The Aphelinus mali scenario also shows that eliciting individual perceptions allows for some understanding that would not be accessible if we had averaged the different parametrizations in a single Bayesian Network model. It is indeed interesting to consider the ambiguity between the conventional producer and the other participants, the former indicating no ecosystem service from an enhanced presence of Aphelinus mali (Fig. 3). The conventional producer explained that the use of a waxing machine takes out fungus stains on apples originating from Woolly aphids honeydew spilling on the fruit. In this sense, this participant is no longer in need from benefits that Aphelinus mali could bring. The use of this machine appears all the more interesting to solve Woolly aphid's damages that the $\mathrm{BN}$ structure indicates no agricultural 
practice that could enhance the presence of Aphelinus mali within apple orchards. It shows that ecosystem services are dependent on the socio-technical situation of each potential beneficiary of an ecosystem service. Many ecosystem service evaluation approaches look at mapping the "supply side" of ecosystem services by assessing the ecosystem functions which sustain potential ecosystem services (Martínez-Harms and Balvanera 2012). This scenario, however, shows that an ecosystem service is not only an ecosystem providing a potentially useful function as it is often suggested but also a need for this benefit. Human needs are changing, and how stakeholders perceive natural enemies as potentially beneficial is influenced by many social factors (Salliou and Barnaud 2017). As a consequence, evaluating ecosystem services requires monitoring the "demand side" of individual human needs for ecological functions at the individual level.

\subsection{Scenario 2: generalist predators' activity is certain}

The generalist predator scenario is based on the certainty that the generalist predators are active within orchards. For all participants except the ecologist, the effect of active generalist predators on the apple production variable is positive, but benefits are very low [from +0.3 to +1.8 ]. There is ambiguity between the ecologist's BN and other participants' BNs as it indicates $\mathrm{a}+6.9$-point increase in the fresh state of the production variable while others indicate almost no gain. Further analysis of impact indicates that for the ecologist, it is both the effect of the reduction of pests "harmful to sales" $(-6.82)$ and a decrease in Woolly aphids "very strong presence" $(-17.4)$, which explain this benefit to farmers. The pedagogic farm manager and organic producer share a similar view that generalist predators' activity relates to the reduction of the probability of "pests harmful to sales" ( -9.7 and -10.2 respectively). The advisor's BN indicates a reduction effect on Woolly aphids (-6.9). The conventional producer's BN indicates, on the contrary, a very significant rise in Woolly aphid presence $(+33.7)$. This is due to the fact that this participant was unable to elicit the probabilities on the effect of active generalist predators on Woolly aphids. As such, this result should be taken with caution.

The generalist predators' scenario shows ambiguity between the ecologist researcher who indicates a higher pest control ecosystem service when compared with other participants. The ecologist's BN in particular indicates an effect of generalist predators by reduction of Woolly aphids' presence and thus reducing the probability of damages on apples. In a previous study we conducted, we found that local stakeholders (whether farmer or advisor) do not mention such predation in their pest management strategy either because they are not aware of the effects of these predators and/or because these effects are locally very weak (Salliou and Barnaud 2017). These local representations differ from scientific findings which mention the significant regulation of generalist predators (Symondson et al. 2002). In particular, generalist predators (especially Exochomus quadripustulatus) may provide early spring control of Woolly aphid's population when Aphelinus mali's first generation is still too limited for significant suppression (Gontijo et al. 2012). Because of such ambiguity between scientific and more local knowledge, our results suggest that there is space for dialogue between ecologists and local stakeholders. They could explore together the possibility to identify and enhance generalist predators which could complement the weak first generation of Aphelinus mali by regulating the early development of Woolly aphids colonies in the season. However, such a dialog might be hindered by an actual systematic broad-spectrum pesticide application against Rosy apple aphid (Dysaphis plantaginea) in early spring.

\subsection{Scenario 3: landscape with a high proportion of semi-natural habitats}

This scenario indicates that, according to the participants, the effect of a landscape with a high proportion of semi-natural habitats on apple production is low or even negative, ranging from -3.2 to +2 points. The pedagogic farm manager's $\mathrm{BN}$ is the only $\mathrm{BN}$ to indicate a slight negative tendency with -3.2 points, which suggests a moderate ambiguity with other participants about the effect of such landscape on natural enemies. As a complementary analysis, Fig. 4 shows the effect of this scenario on the generalist predator variable for each participant.

The ecologist and the organic producer agree on the effect of a landscape with a high proportion of semi-natural habitats on generalist predators $(+10.8$ and +10.7 , respectively), and the conventional producer's $\mathrm{BN}$ indicates a lower but still

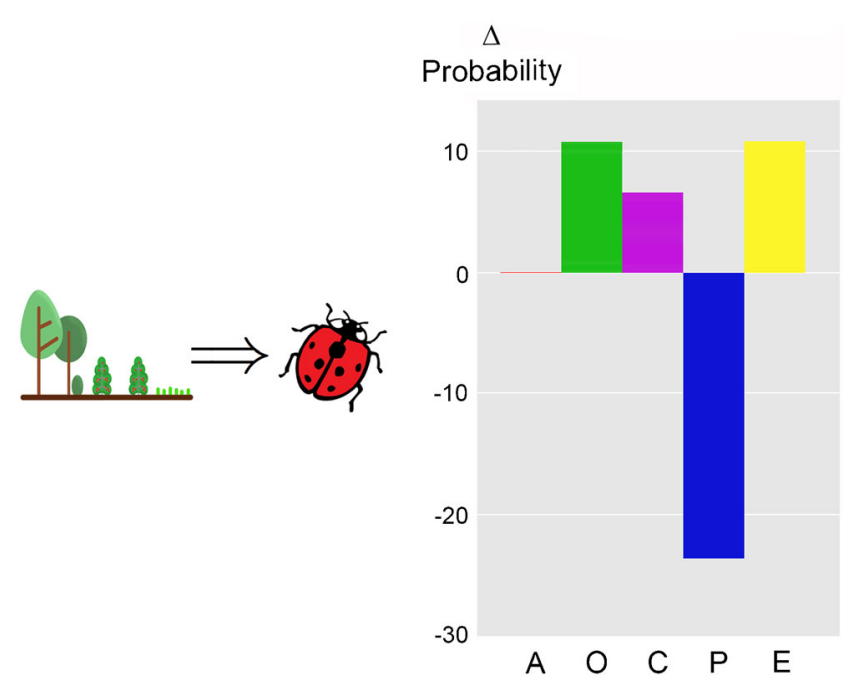

Fig. 4 Effect of the landscape scenario on the "generalist predator" node probability to be on the "active" state according to five participants (A: advisor; O: organic farmer; $\mathrm{C}$ : conventional farmer; P: pedagogic farm manager; E: ecologist) 
positive effect $(+6.6)$. The advisor's BN indicates no effect whatsoever, and the pedagogic farm manager's BN shows a significant decline $(-23.4)$. While there is no ambiguity between the organic producer and the ecologist about the effect of such a landscape on generalist predators' activity, the uncertainty regarding the effect of a landscape with high proportions of semi-natural habitats is significant among all participants. This scenario allowed us to notice that the participants had different representations about the effect of the landscape on insect populations. However, they agreed that pest control ecosystem service that a landscape rich in semi-natural habitats could provide is low (Fig. 3). This suggests that an enhanced natural enemy population does not necessarily lead to an enhanced pest control ecosystem service. This result is coherent with a recent ecological study on apple orchards (Lefebvre et al. 2016). More generally, the prospect to enhance biological pest control by enhancing semi-natural habitats is more and more challenged in agroecology literature (Tscharntke et al. 2016). Our research also challenges this prospect but based on a stakeholder's perspective rather than on an analysis of ecological processes themselves. Results in landscape ecology show that agricultural practices at landscape scale (i.e., density of conventional vs. organic orchards) strongly affect the insect abundances in apple orchards (Bianchi et al. 2013). Our Bayesian models did not indicate such results. Landscapes with a high probability of organic orchards or a high probability of conventional orchards in neighboring fields were also analyzed but showed very limited impact on production. Such results coming from stakeholders' BN are in line with Puech et al. (2015), who established that the amount or organization of farming practices at the landscape scale did not affect natural enemies. Maalouly et al. (2013) suggest that the effects of landscape on pest regulation in orchards is complex, resulting from both the density of conventional/organic fields and of semi-natural habitats while being highly modulated by the agricultural practices at the plot scale.

\subsection{Scenario 4: spontaneous vegetation in the inter-rows of orchards}

The impact on apple production is positive for all participants, from +2.7 to +3.4 , except for the advisor, whose network indicates no effect. Even though the impact is rather limited, all participants except the advisor agree on the positive effect of this agricultural practice on apple production.

Interestingly, even though all participants but the advisor agree on the impact of this scenario on the apple production node, additional analyses show they actually disagree on the main factors explaining this effect. The "inter-row vegetation" node influences three variables in the network: "water," "pollinators," and "generalist predators" (Fig. 2). We analyzed for each participant's $\mathrm{BN}$ indicating a positive impact of this scenario the weight of each of these three nodes on the apple production variable independently. For the organic producer, the main variable explaining a production benefit thanks to the spontaneous vegetation in the inter-rows is related to the pollination service enhancement $(+8.5)$. For the conventional apple producer, the main factor is related to limiting the water deficit probability $(+3.4)$. The pedagogic farm manager relates the benefit from a spontaneous vegetation to all three factors. Finally, for the ecologist, it is mainly the generalist predators and water factors which bring the raise in the production variable $(+10.7$ for less water deficit and +6.9 for more active generalist predators).

Engineering the vegetation in the alleys of apple orchards is promising for farmers but remains very uncertain (Marliac et al. 2015), especially since studies rarely go beyond ecological processes analysis and only rarely evaluate ecosystem services to farmers (Griffiths et al. 2008; Simon et al. 2010). For the group of stakeholders in our study, this practice is probably the most promising as no participant mentions a negative impact. It is especially more promising when compared with landscapescale habitat management (Section 3.3), where benefits are lower or negative and ambiguity remains between the stakeholders about its impact. Even though they agree on the positive effect, the assemblage of factors (water deficit, pollination, and/or pest control) explaining the impact of the inter-row habitat management remains very diverse among participants.

\subsection{Scenario 5: systemic change of all agricultural practices favorable to natural enemies}

This scenario shows that all participants' BNs indicate a positive outcome. The advisor and the conventional apple producer agree that the impact would be very limited $(+1.2$ for both). The pedagogic farm manager and the ecologist agree about a more significant impact $(+6.1$ and +6.6 , respectively). The organic apple producer has an intermediate position (+3.3).

The systemic change scenario shows that all participants consider a positive effect of the scenario grouping together landscape and plot scale agricultural practices as favorable as possible to pest regulation. However, the extra benefit from a radical redesign approach seems rather limited when compared with the sole benefit which may be obtained from the change in a single agricultural practice at the plot scale such as the spontaneous inter-row. Considering such actual views on radical redesign, one can clearly see why participants are reluctant to engage in such a process. The importance of antecedent experiences in farm trajectories eases the transition towards a more systemic redesign of the farm (Lamine 2011). In this regard, promoting experiments at the level of the inter-row vegetation is probably an interesting stepping stone, which many farmers could build on in the future and eventually explore in further steps of a more radical redesign of their farm or their landscape. Because factors explaining the 
benefit of such agricultural practices at the plot scale are diverse among participants, any innovation process about the design of biological control enhancing inter-row should seek to conserve the diversity of perspectives for farmers or innovate with farmers on a case-by-case basis.

\section{Conclusion}

In this paper, we introduced an original approach to explore potential innovations in biological control in apple orchards as perceived by stakeholders in a participatory manner, and this despite many social and ecological uncertainties. Especially, this method made explicit how diverse participating stakeholders consider the effect of habitat management practices at landscape and plot scales on biological control ecosystem services to farmers. Thus, habitat management at the orchard level seems more promising for the participants than at the landscape level, regarding pest control, water availability, and pollination ecosystem services. As habitat management at the landscape scale does not appear to provide significant biological control ecosystem services for local stakeholders, it stresses the need for more landscape ecology studies clearly relating landscape-scale ecological processes to ecosystem services for farmers. By maintaining individual perspectives of stakeholders, our approach was able to shed light on the necessity to integrate individual representations and needs when it comes to ecosystem service assessments. As some ambiguities between stakeholders still remain around the impact of explored agricultural practices on ecological processes and related potential ecosystem services, stakeholders could benefit from a discussion arena to confront their different perspectives and knowledge and eventually to co-design agroecological innovations favorable to biological control. Finally, a limit of our approach is that it was conducted with only five participants. Further research should imply the participation of more stakeholders to get more robust results. In addition, more stakeholders of a same type would allow us to shed light on potential consensus or ambiguity among similar types of stakeholders.

\section{Compliance with ethical standards}

Conflict of interest The authors declare that they have no conflict of interest.

Publisher's note Springer Nature remains neutral with regard to jurisdictional claims in published maps and institutional affiliations.

\section{References}

Bell A, Zhang W, Nou K (2016) Pesticide use and cooperative management of natural enemy habitat in a framed field experiment. Agric Syst 143:1-13. https://doi.org/10.1016/j.agsy.2015.11.012
Bianchi FA, Ives AR, Schellhorn NA (2013) Interactions between conventional and organic farming for biocontrol services across the landscape. Ecol Appl 23(7):1531-1543. https://doi.org/10.1890/ 12-1819.1

Duru M, Therond O, Martin G, Martin-Clouaire R, Magne MA, Justes E, Journet EP, Aubertot JN, Savary S, Bergez JE, Sarthou JP (2015) How to implement biodiversity-based agriculture to enhance ecosystem services: a review. Agron Sustain Dev 35(4):1259-1281. https://doi.org/10.1007/s13593-015-0306-1

Düspohl M, Frank S, Doell P (2012) A review of Bayesian networks as a participatory modeling approach in support of sustainable environmental management. J Sustain Dev 5(12):1-18. https://doi.org/10. 5539/jsd.v5n12p1

Etienne M, Du Toit D, Pollard S (2011) ARDI: a co-construction method for participatory modeling in natural resources management. Ecol Soc 16. https://doi.org/10.5751/ES-03748-160144

Girard N, Navarrete M (2005) Quelles synergies entre connaissances scientifiques et empiriques ? L'exemple des cultures du safran et de la truffe. Nat Sci Soc 13(1):33-44. https://doi.org/10.1051/nss: 2005004

Gontijo LM, Cockfield SD, Beers EH (2012) Natural enemies of Woolly Apple Aphid (Hemiptera: Aphididae) in Washington state. Environ Entomol 41(6):1364-1371. https://doi.org/10.1603/EN12085

Griffiths GJK, Holland JM, Bailey A, Thomas MB (2008) Efficacy and economics of shelter habitats for conservation biological control. Biol Control 45(2):200-209. https://doi.org/10.1016/j.biocontrol. 2007.09.002

Hill SB, MacRae RJ (1995) Conceptual framework for the transition from conventional to sustainable agriculture. J Sustain Agric 7(1):81-87. https://doi.org/10.1300/J064v07n01_07

Horton DR, Broers DA, Lewis RR, Granatstein D, Zack RS, Unruh TR, Moldenke AR, Brown JJ (2003) Effects of mowing frequency on densities of natural enemies in three Pacific Northwest pear orchards. Entomol Exp Appl 106(2):135-145. https://doi.org/10. 1046/j.1570-7458.2003.00018.x

Lamine C (2011) Transition pathways towards a robust ecologization of agriculture and the need for system redesign. Cases from organic farming and IPM. J Rural Stud 27(2):209-219. https://doi.org/10. 1016/j.jrurstud.2011.02.001

Lefebvre M, Franck P, Toubon J-F et al (2016) The impact of landscape composition on the occurence of a canopy dwelling spider depends on orchard management. Agric Ecosyst Environ 169:33-42. https:// doi.org/10.1016/j.agee.2013.02.008

Maalouly M, Franck P, Bouvier J-C, Toubon JF, Lavigne C (2013) Codling moth parasitism is affected by semi-natural habitats and agricultural practices at orchard and landscape levels. Agric Ecosyst Environ 169:33-42. https://doi.org/10.1016/j.agee.2013. 02.008

Marliac G, Simon S, Mazzia C, Penvern S, Lescourret F, Capowiez Y (2015) Increased grass cover height in the alleys of apple orchards does not promote Cydia pomonella biocontrol. BioControl 60(6): 805-815. https://doi.org/10.1007/s10526-015-9687-y

Martínez-Harms MJ, Balvanera P (2012) Methods for mapping ecosystem service supply: a review. Int J Biodiver Sci Ecosyst Serv Manag 8(1-2):17-25. https://doi.org/10.1080/21513732.2012.663792

Meynard J-M, Dedieu B, Bos AP (2012) Re-design and co-design of farming systems. An overview of methods and practices. In: Darnhofer I, Gibbon D, Dedieu B (eds) Farming systems research into the 21st century: the new dynamic. Springer Netherlands, Dordrecht, pp 405-429. https://doi.org/10.1007/978-94-007-4503218

Mols PJM (1996) Do natural enemies control woolly aphid? In: Acta Horticulturae. In: International Society for Horticultural Science (ISHS). Leuven, Belgium, pp 203-207. https://doi.org/10.17660/ ActaHortic.1996.422.34 
Ortiz-Martínez SA, Ramírez CC, Lavandero B (2013) Host acceptance behavior of the parasitoid Aphelinus mali and its aphid-host Eriosoma lanigerum on two Rosaceae plant species. J Pest Sci 86(4):659-667. https://doi.org/10.1007/s10340-013-0518-6

Puech C, Poggi S, Baudry J, Aviron S (2015) Do farming practices affect natural enemies at the landscape scale? Landsc Ecol 30(1):125-140. https://doi.org/10.1007/s10980-014-0103-2

Rusch A, Chaplin-Kramer R, Gardiner MM et al (2016) Agricultural landscape simplification reduces natural pest control: a quantitative synthesis. Agric Ecosyst Environ 221:198-224. https://doi.org/10. 1016/j.agee.2016.01.039

Salliou N, Barnaud C (2017) Landscape and biodiversity as new resources for agro-ecology? Insights from farmers' perspectives. Ecol Soc 22. https://doi.org/10.5751/ES-09249-220216

Salliou N, Barnaud C, Vialatte A, Monteil C (2017) A participatory Bayesian belief network approach to explore ambiguity among stakeholders about socio-ecological systems. Environ Model Softw 96:199-209. https://doi.org/10.1016/j.envsoft.2017.06.050

Schellhorn NA, Gagic V, Bommarco R (2015) Time will tell: resource continuity bolsters ecosystem services. Trends Ecol Evol 30(9):524 530. https://doi.org/10.1016/j.tree.2015.06.007

Sigwalt A, Pain G, Pancher A, Vincent A (2012) Collective innovation boosts biodiversity in French vineyards. J Sustain Agric 36(3):337352. https://doi.org/10.1080/10440046.2011.654008

Simon S, Bouvier J-C, Debras J-F, Sauphanor B (2010) Biodiversity and pest management in orchard systems. A review. Agron Sustain Dev 30(1):139-152. https://doi.org/10.1051/agro/2009013
Stallman HR, James HS (2015) Determinants affecting farmers' willingness to cooperate to control pests. Ecol Econ 117:182-192. https:// doi.org/10.1016/j.ecolecon.2015.07.006

Steingröver EG, Geertsema W, van Wingerden WKRE (2010) Designing agricultural landscapes for natural pest control: a transdisciplinary approach in the Hoeksche Waard (The Netherlands). Landsc Ecol 25(6):825-838. https://doi.org/10.1007/s10980-010-9489-7

Symondson WOC, Sunderland KD, Greenstone MH (2002) Can generalist predators be effective biocontrol agents? Annu Rev Entomol 47(1):561-594. https://doi.org/10.1146/annurev.ento.47.091201. 145240

Tscharntke T, Karp DS, Chaplin-Kramer R, Batáry P, DeClerck F, Gratton C, Hunt L, Ives A, Jonsson M, Larsen A, Martin EA, MartínezSalinas A, Meehan TD, O'Rourke M, Poveda K, Rosenheim JA, Rusch A, Schellhorn N, Wanger TC, Wratten S, Zhang W (2016) When natural habitat fails to enhance biological pest control - five hypotheses. Biol Conserv 204:449-458. https://doi.org/10.1016/j. biocon.2016.10.001

Veres A, Petit S, Conord C, Lavigne C (2013) Does landscape composition affect pest abundance and their control by natural enemies? A review. Agric Ecosyst Environ 166:110-117. https://doi.org/10. 1016/j.agee.2011.05.027

Weber DC, Brown MW (1988) Impact of Woolly Apple Aphid (Homoptera: Aphididae) on the growth of potted apple trees. J Econ Entomol 81(4):1170-1177. https://doi.org/10.1093/jee/81.4. 1170 